\title{
Parasitic Contamination on Raw Vegetables Sold in Selected Open Markets in Ekiti, Southwest Nigeria
}

\author{
Hammed O. Mogaji ${ }^{*}$, Ashiat Y. Ishola ${ }^{1}$, Oladunni N. Adekunle ${ }^{2}$, Modinat A. Adekoya ${ }^{3}$, \\ Funmilayo S. Oluwafemi ${ }^{4}$, Oluwafemi A. Ajayi ${ }^{1}$, Ikenna M. Odoh ${ }^{5}$ and Uwem F. Ekpo ${ }^{6}$ \\ ${ }^{I}$ Department of Animal and Environmental Biology, Federal University Oye-Ekiti, Ekiti State, \\ Nigeria, \\ ${ }^{2}$ Department of Zoology, Olabisi Onabanjo University Ago-Iwoye, Ogun State, \\ ${ }^{3}$ Department of Plant Science and Biotechnology, Federal University Oye-Ekiti, Ekiti State, \\ Nigeria \\ ${ }^{4}$ Department of Public Health, Afe Babalola University, Ado-Ekiti, Ekiti State, Nigeria \\ ${ }^{5}$ University Medical Centre, Federal University Oye-Ekiti, Ekiti State, Nigeria, \\ ${ }^{6}$ Department of Pure and Applied Zoology, Federal University of Agriculture, Abeokuta, Ogun \\ State, Nigeria
}

*Correspondence should be addressed to Hammed O. Mogaji: mogajihammed@gmail.com

Received 22nd October 2021; Revised 19th November 2021; Accepted 25th November 2021

(C) 2021 Mogaji et al. Licensee Pan African Journal of Life Sciences an official publication of Faculty of Basic Medical Sciences, Ladoke Akintola University of Technology, Ogbomoso. This is an Open Access article distributed under the terms of the Creative commons Attribution License (https://creativecommons.org/licenses/BY/4.0), which permits unrestricted use, distribution, and reproduction in any medium, provided the original work is properly cited.

\begin{abstract}
Background: Infections arising from the consumption of parasite-contaminated vegetables are a major concern in public health. This study assessed the parasitic contamination of vegetables sold across open markets in Ekiti, Nigeria

Methods: A total of 88 samples of 6 different vegetables: African spinach (A maranthus hybridus), pumpkin (Telfairia occidentalis), Jute leaf (Corchorus olitorus), Sierra Leone bologi leaf (Solanecio biafrae), Yoruba bologi leaf (Crassocephalum ruben), and Waterleaf (Talinum triangulare) were purchased from 42 vendors selected using a snow-ball sampling approach. About 200g of each sample was processed using sedimentation technique and observed for parasites eggs/ ova under the microscope. Data obtained were analyzed using SPSS version 20.

Results: A total of 9 parasites were recovered, with an overall prevalence of $53.4 \%(\mathrm{n}=45)$. Nematodes were the most predominant $(45,51.1 \%)$. By species, the recovered eggs/larvae of hookworms were more (27, 30.7\%), compared to Ascaris spp. $(22,25.0 \%)$ and Strongyloides spp $(17,19.3 \%)(\mathrm{p}=0.00)$. Amaranthus hybridus was the most contaminated $(15,75 \%)$, followed by Crassocephalum ruben $(10,62.5 \%)(\mathrm{p}=0.05)$. The majority of the contaminated vegetables were from Ifaki market $(15,75 \%)$.
\end{abstract}

Conclusion: This study, therefore, highlights the need to intensify efforts at improving hygienic practices among farmers and consumers in these areas.

Keywords: Parasites, contamination, Vegetables, Markets, Ekiti, Nigeria 


\subsection{INTRODUCTION}

Vegetables are plants whose parts are edible either in their raw state or in a minimally processed form, as defined by the International Year of Fruits and Vegetables (IYFV) [1]. On a global scale, about 3.9 million deaths were attributed to insufficient intake of fruits and vegetables in 2017 [2]. Approximately 14 percent of such deaths were due to gastro-intestinal cancer, 11 percent to ischemic heart disease, and about 9 $\%$ caused by stroke [3]. Therefore, the World Health Organization (WHO) recommends daily consumption of at least $400 \mathrm{~g}$ of vegetables to maximize health and nutritional benefits [4]. The health benefits of vegetables are enormous as they provide vitamins, minerals and phytochemicals that function as antioxidants, phytoestrogens, and anti-inflammatory agents. In addition, vegetables are a good source of dietary fiber, which is linked to a lower incidence of cardiovascular disease and obesity $[5,6]$.

Despite the tremendous benefits of vegetable consumption on human health, there are concerns about the safety of vegetables produced by farmers in rural and some urban settings of developing and underdeveloped countries $[7,8]$. In these areas, vegetables are mainly cultivated on untreated soils, using human or animal excreta as a natural fertilizer and untreated wastewater for irrigation [8-12]. In most cases, after being harvested, these vegetables are consumed raw or processed minimally with less heat or washing to retain the natural taste and preserve heat liable nutrients [13]. This poor hygienic practice promotes the transmission of parasitic eggs to the human host. In other instances, contamination of vegetables may occur during or after harvesting, with farmers preserving the vegetable through the intermittent sprinkling of unclean water [14].

Intestinal parasites such as Ascaris lumbricoides, Cryptosporidium spp, Cyclospora spp Entamoeba histolytica, Enterobius vermicularis, Fasciola spp, Giardia lambia, Hookworms, Hymenolepis spp, Strongyloides stecoralis, Taenia spp, Trichuris trichiura, and Toxocara spp. have been reported on various items of vegetable samples in Nigeria [13,15-18], Iran [11,12], Ethiopia [8] and Egypt [9]. The diseases caused by the majority of these parasites have been classified as neglected by the WHO, thereby calling for more concrete actions in the public health domain, especially on their control and possible elimination [19]. To complement the ongoing control and elimination effort, there is a need to continuously gather prevalence data and monitor transmission pathways, especially in areas where such data are lacking [20].

Despite the plethora of studies reporting parasitic contamination of vegetables in Nigeria [13,15-18], few or no studies report the parasitic contamination of vegetables sold at different open markets in Ekiti, Southwest Nigeria. Hence, the present study aimed to address this gap in information by assessing the parasitic contamination of vegetables across selected open markets on the popular Ifaki-Osin route in Ekiti State, Nigeria.

\subsection{METHODOLOGY}

\subsection{Study Area}

This study was conducted in Ekiti State, Nigeria, between June and October 2019. Ekiti State is one of the six southwestern states in Nigeria. The state has a total land area of $5887.890 \mathrm{sqkm}$ and is administratively divided into 16 local government areas (LGAs), with the capital located at Ado-Ekiti. Generally, the population of Ekiti state was estimated to be 3,366,750 in 2019, with an annual growth rate of $2.68 \%$. The primary occupation of the inhabitants is farming, and trading, with only 3 urbanized LGAs, characterized by the presence of roads, tertiary institutions, and industries. One of the most dominant routes is the Ifaki - Osin route that connects Ekiti state with Kogi State. The population of inhabitants across this route has also grown in the last 8 years due to establishing a tertiary institution, thus attracting more open market stands in such areas.

\subsection{Sample Collection}

Vegetable samples were collected from five open markets across the Ifaki - Osin route, namely, Ifaki, Oye, Itapa, Ilupeju, and Osin. The collected vegetables were identified to their common names in the Department of Plant Science and Biotechnology, Federal University Oye-Ekiti as African spinach (Amaranthus hybridus), pumpkin (Telfairia occidentalis), Jute leaf (Corchorus olitorus), Sierra Leone bologi leaf (Solanecio biafrae), Yoruba bologi leaf (Crassocephalum ruben), and Waterleaf (Talinum triangulare). The samples were collected once in each market using a snow-ball approach from vegetable vendors. Three vegetable bunches were purchased from each vendor, with a purposive selection from the top, middle, and bottom layers of the heap of vegetable bunch displayed for sale. Collected vegetables 
were put into sterile bags and appropriately labeled with an identification number unique to the market and vendor. Samples were transported in a cold box within 2 hours of collection to the Parasitology laboratory in the Department of Animal and Environmental Biology at Federal University Oye-Ekiti for processing.

\subsection{Laboratory processing of collected samples}

Collected samples were processed using sedimentation techniques. Approximately 200 grams of each vegetable was soaked (for 15 minutes) in $1 \mathrm{~L}$ of $10 \mathrm{ml}$ physiological saline, followed by manual shaking to detach the parasite stages (ova, larvae, cysts, and oocysts). The vegetable samples were removed, and the resulting washing water was transferred into another sterile transparent bucket. After overnight sedimentation of the washing solution, 10 milliliters of the sediment were transferred to two different centrifuge tubes using a sieve to remove undesirable matter. For concentrating the parasite stages (ova, larvae, cysts, and oocysts), the first tube was centrifuged at 3000 revolutions for five minutes. After centrifugation, the supernatant was decanted carefully without shaking. Then, the sediment was agitated gently by hand to redistribute the parasitic stages. Pasteur pipette was used to place sediment drops on a clean grease-free slide and observed under the microscope using the $\mathrm{x} 10$ and $\mathrm{x} 40$ objective lens. The eggs and larvae were identified based on morphological details described by Chiodini et al., [21].

Table 1. Background Information on Vegetables Sampled

\begin{tabular}{llll}
\hline $\begin{array}{l}\text { Vegetable } \\
\text { type }\end{array}$ & $\begin{array}{l}\text { Common } \\
\text { name }\end{array}$ & $\begin{array}{l}\text { Number } \\
\text { of vendors (\%) }\end{array}$ & $\begin{array}{l}\text { Number of } \\
\text { vegetables sampled } \\
(\%)\end{array}$ \\
\hline $\begin{array}{l}\text { Telfairia } \\
\text { occidentalis }\end{array}$ & $\begin{array}{l}\text { Pumpkin } \\
\text { leaf }\end{array}$ & $5(11.9)$ & $12(13.6)$ \\
$\begin{array}{l}\text { Amaranthus } \\
\text { hybridus }\end{array}$ & $\begin{array}{l}\text { African } \\
\text { spinach }\end{array}$ & $16(38.1)$ & $20(22.7)$ \\
$\begin{array}{l}\text { Solanecio } \\
\text { biafrae }\end{array}$ & $\begin{array}{l}\text { Sierra } \\
\text { Leone } \\
\text { bologi }\end{array}$ & $2(4.8)$ & $8(9.1)$ \\
leaf & $\begin{array}{l}\text { Yoruba } \\
\text { bologi } \\
\text { leaf }\end{array}$ & $4(9.5)$ & $16(18.2)$ \\
$\begin{array}{l}\text { Crassocepha- } \\
\text { lum rubens }\end{array}$ & Water leaf & $7(16.7)$ & $16(18.2)$ \\
$\begin{array}{l}\text { Talinum } \\
\text { triangulare }\end{array}$ & Jute leaf & $8(19.0)$ & $16(18.2)$ \\
$\begin{array}{l}\text { Corchorus } \\
\text { olitorius }\end{array}$ & & $42(100)$ & $88(100)$ \\
Total & & & \\
\hline
\end{tabular}

Table 2. Overall Prevalence of Intestinal Parasites Recovered from the Vegetables Sampled

\begin{tabular}{lllll}
\hline Category & Parasite & NE & NP (\%) & $\begin{array}{l}\text { p- } \\
\text { value }\end{array}$ \\
\hline Nematodes & Ascaris spp. & 88 & $22(25.0)$ & 0.000 \\
& Trichuris spp. & 88 & $2(2.3)$ & \\
& Hookworms & 88 & $27(30.0)$ & \\
& Enterobius spp & 88 & $2(2.3)$ & \\
& Strongyloides spp & 88 & $17(19.3)$ & \\
& $\begin{array}{l}\text { Overall preva- } \\
\text { lence* }\end{array}$ & 88 & $45(51.1)$ & \\
Platyhelminthes & Fasciola spp & 88 & $4(4.5)$ & 0.59 \\
& Paragonimus spp & 88 & $2(2.3)$ & \\
& Taenia spp & 88 & $2(2.3)$ & \\
& $\begin{array}{l}\text { Overall preva- } \\
\text { lence* }\end{array}$ & 88 & $6(6.8)$ & \\
Protozoans & Protozoan cyst & 88 & $2(2.3)$ & - \\
lence* & Overall preva- & 88 & $2(2.3)$ & \\
& lence* & 88 & $47(53.4)$ & \\
& & & & \\
\hline
\end{tabular}

NE: Number of vegetables examined; ${ }^{*}$ The overall prevalence estimates included an algorithm which considered mixed infection

\subsection{Data Analysis}

Data obtained were entered into Microsoft Excel version 2017. Statistical analysis was performed with SPSS version 20.0. Descriptive statistics such as frequencies and percentages were used to estimate proportions. The difference in parasitic contamination among the different categories (i.e., markets and vegetables) was compared using the Pearson's chi-square test $\left(\chi^{2}\right)$ and Fisher's exact test, where appropriate. Statistical significance was established when the p-value is less than 0.05

\subsection{Ethical Approval}

The study protocol was reviewed by the Ethics review committee of the Department of Animal and Environmental Biology, Federal University Oye-Ekiti. Prior to data collection, visitations were made to the market leaders in each selected site, where the objectives and study procedures were explained, and permissions for field surveys were sought. Verbal informed consents were obtained from vendors before purchasing the vegetables.

\subsection{RESULTS}

\subsection{Background Information on Vegetables Sampled}


Table 3. Prevalence of Intestinal Parasites by Vegetable Types

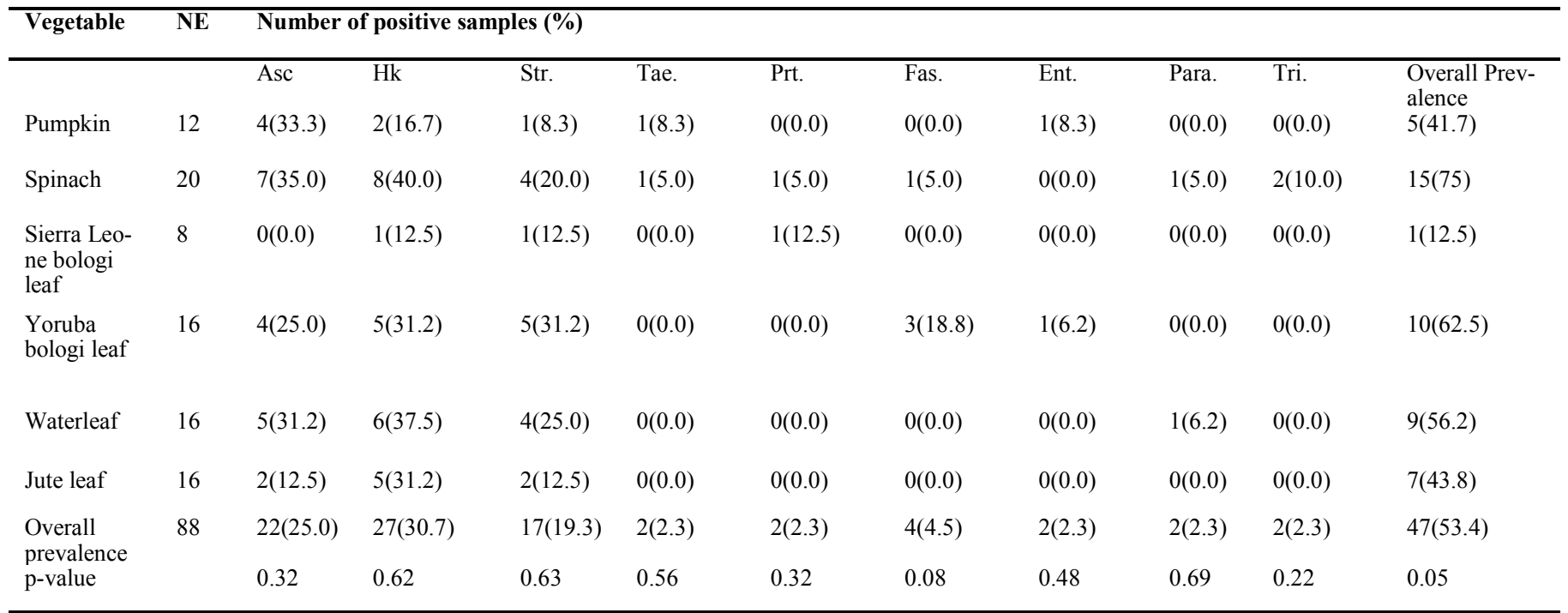

NE: Number of vegetables examined; NP: Number positive; Asc: Ascaris spp; Hk: Hookworms; Str: Strongyloides; Tae: Taenia spp; Prt: Protozoan cyst; Fas: Fasciola spp; Para: Paragonimus spp; Tri: Trichuris spp. ${ }^{*}$ The overall prevalence estimates included an algorithm which considered mixed infection

A total of 88 vegetables including African spinach (20, $22.7 \%)$, pumpkin $(12,13.6 \%)$, Jute leaf $(16,18.2 \%)$, Yoruba bologi leaf $(16,18.2 \%)$, Waterleaf $(16,18.2 \%)$ and Sierra Leone bologi leaf $(8,9.1 \%)$ was collected and examined. The vegetables were sourced from 42 different vendors, with the majority of the vendors trading African spinach $(16,38.1 \%)$, and the least traded vegetable was the Sierra Leone bologi leaf $(2,4.8 \%)$ (Table 1).

\subsection{Prevalence of Intestinal Parasites by Vegetable Types Across the Study Markets}

An overall prevalence of $53.4 \%(n=47)$ was observed for intestinal parasites across the study markets and sampled vegetables. Across the categories of parasitic eggs/larva recovered, nematodes were higher in number (45, $51.1 \%)$, compared to Platyhelminthes $(6,6.8 \%)$ and protozoans $(2,2.3 \%)$ (Table 2$)$. By species' prevalence, the eggs/larva of hookworms was the most predominant of all the parasitic eggs recovered $(27,30.7 \%)$, followed by Ascaris spp. (22, 25.0\%), Strongyloides (17, 19.3\%) and Fasciola spp. (4, 4.5\%). There were no significant differences in the species prevalence observed across the vegetables sampled $(\mathrm{p}>0.05)$ (Table 2). For the vegetables examined, African spinach was the most contaminated $(15,75 \%)$, followed by Yoruba bologi leaf $(10,62.5 \%)$, waterleaf $(9,56.2 \%)$, Jute leaf $(7,43.8 \%)$, pumpkin $(5$, $41.7 \%)$ and Sierra Leone bologi leaf $(1,12.5 \%)$. There were no significant differences in the overall prevalence

Table 4. Prevalence of Intestinal Parasites by Study Markets

\begin{tabular}{|c|c|c|c|c|c|c|c|c|c|c|c|}
\hline \multirow{2}{*}{$\begin{array}{l}\text { Mar- } \\
\text { kets }\end{array}$} & \multirow[t]{2}{*}{$\mathbf{N E}$} & \multicolumn{10}{|c|}{ Number of positive samples (\%) } \\
\hline & & Asc & $\mathrm{Hk}$ & Str. & Tae. & Prt. & Fas. & Ent. & Para. & Tri. & $\begin{array}{l}\text { Overall Preva- } \\
\text { lence }\end{array}$ \\
\hline Oye & 16 & $1(6.2)$ & $1(6.2)$ & $1(6.2)$ & $0(0.0)$ & $0(0.0)$ & $0(0.0)$ & $0(0.0)$ & $0(0.0)$ & $0(0.0)$ & $1(6.2)$ \\
\hline Ilupeju & 20 & $4(20.0)$ & $9(45.0)$ & $1(5.0)$ & $0(0.0)$ & $0(0.0)$ & $0(0.0)$ & $0(0.0)$ & $0(0.0)$ & $0(0.0)$ & $11(55.5)$ \\
\hline Itapa & 12 & $2(16.7)$ & $3(25.0)$ & $2(6.7)$ & $1(8.3)$ & $2(16.7)$ & $2(16.7)$ & $1(8.3)$ & $1(8.3)$ & $2(16.7)$ & $8(66.7)$ \\
\hline Ifaki & 20 & $9(45.0)$ & $10(50.0)$ & $8(40.0)$ & $0(0.0)$ & $0(0.0)$ & $1(5.0)$ & $1(5.0)$ & $1(5.0)$ & $0(0.0)$ & $15(75)$ \\
\hline Osin & 20 & $6(30.0)$ & $4(20.0)$ & $5(25.0)$ & $1(5.0)$ & $0(0.0)$ & $1(5.0)$ & $0(0.0)$ & $0(0.0)$ & $0(0.0)$ & $12(60)$ \\
\hline $\begin{array}{l}\text { Overall } \\
\text { preva- } \\
\text { lence }\end{array}$ & 88 & $\begin{array}{l}22 \\
(25.0)\end{array}$ & $27(30.7)$ & $\begin{array}{l}17 \\
(19.3)\end{array}$ & $2(2.3)$ & $2(2.3)$ & $4(4.5)$ & $2(2.3)$ & $2(2.3)$ & $2(2.3)$ & $47(53.4)$ \\
\hline$P$ value & & 0.08 & $0.03 *$ & $0.04 *$ & 0.41 & $0.01 *$ & 0.22 & 0.41 & 0.41 & $0.01 *$ & $0.01 *$ \\
\hline
\end{tabular}

NE: Number of vegetables examined; Asc: Ascaris spp; Hk· Hookworms; Str: Strongyloides; Tae: Taenia spp; Prt: Protozoan cyst; Fas: Fasciola spp; Para: Paragonimus spp; Tri: Trichuris spp. *The overall prevalence estimates included an algorithm which considered mixed infection 
of intestinal parasites across the vegetables sampled $(\mathrm{p}=$ 0.05) (Table 3). In addition, Ifaki market had the highest prevalence of parasite contamination $(15,75 \%)$, followed by Itapa $(8,66.7 \%)$, Osin $(12,60 \%)$, Ilupeju $(11,55.5 \%)$, and Oye $(1,6.2 \%)$. There were also significant differences across the overall prevalence of intestinal parasites across the study communities $(p=0.01)$ (Table 4$)$. Of the five markets, only Itapa has at least one record of infection for each of the parasites observed. The prevalence of intestinal parasites was significantly different for hookworm $(\mathrm{p}=0.03)$, Strongyloides spp $(\mathrm{p}=0.04)$, protozoans $(\mathrm{p}=0.01)$, and Trichuris spp $(\mathrm{p}=0.01)$ across all the study markets.

\subsection{DISCUSSION}

This study assessed the parasitic contamination status of vegetables across the open markets situated along the Ifaki -Osin route in Ekiti State, Nigeria. The overall prevalence reported here $(53.4 \%)$ is lower than the $73.5 \%$ reported in a similar study across open markets in Abeokuta [13]. However, the prevalence is higher than those reported in Lafia (37.5\%), Plateau (36.05), Oyo (35.4\%) and Ibadan (11.6\%) [17,18,22,23]. The disparities in the prevalence reports across the study could be due to variations in the number of samples collected, type of samples, or methods employed in processing samples [20]. In addition, the differences might have been influenced by varying environmental conditions and poor hygienic practices of the farmers. Lack of toilet facilities that are characteristic of most rural areas predisposes people to open defecation habits on farm soils used for planting [24]. This act, coupled with usage of organic manures during planting and poor personal and domestic hygiene, are probable factors that vary across locations and aid the development of parasites on soil and subsequent transmission to humans through vegetables [13].

The majority of the parasitic contamination was from nematodes. For instance, all the vegetables examined had high contamination ( $>40 \%$ ) except the Sierra Leone bologi leaf, which reiterates the fact that vegetables are prone to contamination, majorly because the edible parts of these plants are grown closer to the soil [25]. Their rough surfaces facilitate better attachment of parasites eggs or larva, providing them better anchorage to overcome the effects of washing $[20,26]$. Furthermore, many vegetable vendors may also wash their vegetables minimally to pre- vent damage or cuts off the fragile leaves. This practice, therefore, supports the retention of the eggs or larva after harvest [27]. Unlike other vegetables, the Sierra Leone bologi leaf had the least parasite contamination, and this observation has been reported in a similar study conducted in Akure, southwest Nigeria [28]. This vegetable is the least traded among the five vegetables sold across the study markets, with only 2 of the 42 traders displaying this vegetable for purchase. This may reflect poor consumption preference, leading to reduced effort in activities that could improve yield, for instance, use of organic manures.

The prevalence of A scaris spp recovered in this study is high and comparable with similar studies in Lafia [17] and Abeokuta [13]. The preponderance of Ascaris lumbricoides infection could be attributed to its ability to withstand harsh and unfavorable environmental conditions [29]. However, unlike other studies [13,17], the most predominant parasitic contamination in this study was caused by hookworms. This finding is similar to the epidemiological reports in Abeokuta [30], where hookworm was the most predominant infection found among human subjects examined, thus reiterating the differences in space regarding the ecological suitability of the soil for the transmission of soil nematodes. Similar to other studies, we found the occurrence of Strongyloides spp. The prevalence reported here is higher than that reported in Ethiopia [20]. This observation might have been influenced by the dual life stages of the worm, with the freeliving stage reported to be abundant on soils $[31,32]$.

This study has shown the presence of parasitic contamination on vegetables sold across the open markets surveyed. This reflects the ecological suitability of the farmlands used to cultivate the vegetables sampled. Ifaki market serves as an entry point to the Ifaki-Osin route from the south and appears to be more populated than the other markets because of its geographic positioning. This market recorded the most parasitic contamination, followed by the Itapa market. Efforts targeted at improving hygienic practices among farmers and consumers in these areas is therefore important, and is in tandem with 2021 International Year of Fruits and Vegetable declaration [1] to raise awareness of the nutritional and health benefits of fruit and vegetables and their contribution to a balanced and healthy diet and lifestyle. 


\section{Acknowledgements}

We are grateful to the market women and vegetable vendors who assisted in the sample collection process. We also appreciate the technologists from the Department of Plant Science and Biotechnology, who helped with the taxonomic classification of the vegetable samples

\section{Conflicts of Interest}

The authors declare no competing interests.

\section{Authors' Contributions}

HOM conceived and designed the study, contributed to data collection, data analysis tools, analysis of data and manuscript writing. AYI contributed to data collection, analysis of data and manuscript writing. ONA contributed to data analysis tools and manuscript writing. AMA, OSF, OAA contributed to data collection, data analysis tools and manuscript writing. IMO contributed to data analysis tools, analysis of data and manuscript writing. UFE contributed to data analysis tools and manuscript writing. All authors approved the final copy of the manuscript

\section{References}

1. Food and Agricultural Organization of the United Nations (FAO). Fruit and vegetables - your dietary essentials. The International Year of Fruits and Vegetables 2021. Background Paper. Rome. 2020. Available at https:// doi.org/10.4060/cb2395en

2. World Health Organization (WHO). Increasing fruit and vegetable consumption to reduce the risk of noncommunicable diseases. e-Library of Evidence for Nutrition Actions (eLENA). 2019. Available at www.who.int/ elena/titles/fruit_vegetables_ncds/en/\#

3. Afshin A, Sur PJ, Fay KA, Cornaby L, Ferrara G., Salama JS. et al. Health effects of dietary risks in 195 countries, 1990-2017: A systematic analysis for the Global Burden of Disease Study 2017. Lancet. 2019;393(10184):1958-72. Available at www.thelancet.com/article/S0140-6736(19) 30041-8/fulltext

4. World Health Organization (WHO). Diet, Nutrition and the prevention of chronic diseases. Report of a joint FAOWHO Expert Consultation, Geneva, World Health Organization, 2003 (WHO Technical Report Series, No, 916).

5. Slavin JL, Lloyd B. Health benefits of fruits and vegetables. Adv Nutr. 2012;3(4):506-516. https:// doi.org/10.3945/an.112.002154

6. Siegel KR, Ali MK, Srinivasiah A, Nugent RA. Narayan
KMV. Do we produce enough fruits and vegetables to meet global health need?. PLoS One. 2014;9(8):e104059.

7. Ametepey ST, Cobbina SJ, Akpabey FJ, Duwiejuah AB, Abuntori ZN. Health risk assessment and heavy metal contamination levels in vegetables from Tamale Metropolis, Ghana. Int J Food Conntam. 2018;5(5). https:// doi.org/10.1186/s40550-018-0067-0

8. Bekele F, Tefera T, Biresaw G, Yohannes T. Parasitic contamination of raw vegetables and fruits collected from selected local markets in Arba Minch town, Southern Ethiopia. Infect. Dis. Poverty. 2017;6(1):1-7. doi:10.1186/ s40249-016-0226-6 16.

9. Eraky M, Rashed S, Nasr M, El-Hamshary A, Salah ElGhannam A. Parasitic contamination of commonly consumed fresh leafy vegetables in Benha, Egypt. J Parasitol Research. 2014;7:1-8. doi:10.1155/2014/613960

10. Amoah P, Drechsel P, Abaidoo RC, Abraham EM. Improving food hygiene in Africa where vegetables are irrigated with polluted water: paper presented for the West Africa Regional Sanitation and Hygiene Symposium. 10-12 November 2009, Accra, Ghana

11. Fallah A, Pirali-Kheirabadi K, Shirvani F, Saei-Dehkordi S. Prevalence of parasitic contamination in vegetables used for raw consumption in Shahrekord, Iran: influence of season and washing procedure. Food Control. 2012;25(2):617620. doi:10.1016/j. foodcont.2011.12.004

12. Siyadatpanah A, Tabatabaei F, Zeydi A, Spotin A, FallahOmrani V, Assadi M, Moradi S, Rostami A, Memari F, Hajialiani F. Parasitic contamination of raw vegetables in Amol, North of Iran. Arch Clin Infect Dis. 2013;8 (2):e15983 doi:10.5812/archcid.15983

13. Fagbenro MT, Mogaji HO, Oluwole AS, Adeniran AA, Alabi OM, Ekpo UF. Prevalence of Parasites found on Vegetables and Perception of Retailers and Consumers about Contamination in Abeokuta Area of Ogun State, Nigeria. Clinical Microbiology and Case Reports. 2016;2(1):1 $-5$

14. Ofor MO, Okorie VC, Ibeawuchi II, Ihejirika GO, Obilo OP, Dialoke SA. Microbial contaminant in fresh tomato wash water and food safety consideration in south-eastern Nigeria. Life Science Journal. 2009;6(3):80-82

15. Yakubu DP, Dawet A, Jiya V. Prevalence of cyst and ova of enteric parasites associated with Amaranthus spp (Spinanch) in Jos north local government area, Plateau State, Nigeria. Niger J Parasitol. 2013;34(1):131-155.

16. Ohaeri CC, Chilaka AE. Control of geohelminths in contaminated fruits and vegetables using different washing agent in Umuahia Abia state, Nigeria. Niger J Parasitol. 2013;34(1):91-96. 
17 Abe EM, Ajah LJ, Ayuba SOO, Mogaji HO and Ekpo UF.

Mogaji et al Pan African Journal of Life Sciences (2021): 5(3): 342-348

Geohelminths Contamination of Fruits and Vegetables Sold in Lafia Markets. Annu Res Rev Biol. 2016;11(2):18

18 Abe EM, Ajah LJ, Ayuba SOO, Mogaji HO and Ekpo UF. Geohelminths Contamination of Fruits and Vegetables Sold in Lafia Markets. Annu Res Rev Biol. 2016;11(2):18

19 Adejumoke A, Morenikeji O. Prevalence of intestinal parasites in vegetables sold in major markets in Ibadan city, south-west Nigeria. GJPAS. 2015;21(1):7-12. 2.

20 Hotez PJ, Kamath A. Neglected Tropical Diseases in SubSaharan Africa: Review of Their Prevalence, Distribution, and Disease Burden. PLoS Negl Trop Dis. 2009;3(8): e412.

21 Alemu G, Nega M, Alemu M. Parasitic Contamination of Fruits and Vegetables Collected from Local Markets of Bahir Dar City, Northwest Ethiopia. Res Rep Trop Med. 2020;11:17-25. doi:10.2147/RRTM.S244737

22 Chiodini PL, Moody AH, Manser DW. Atlas of medical helminthology and protozoology. Churchill Livingstone, Fourth Edition. 2001;4-10.

23 Damen J, Banwat E, Egah D, Allanana J. Parasitic contamination of vegetables in Jos, Nigeria. Ann Afr Med. 2007;6(3):115. doi:10.4103/ 15963519.55723

24 Alli JA, Abolade GO, Kolade AF, Salako AO. Prevalence of intestinal parasites on fruits available in Ibadan markets, Oyo State, Nigeria. Acta Parasitol Glob. 2011;2(1):6 -10 .

25 Osumanu, IK, Kosoe, EA and Ategeeng F. Determinants of Open Defecation in the Wa Municipality of Ghana: Empirical Findings Highlighting Sociocultural and Economic Dynamics among Households. J Environ Pub
Health. 2019;1-10 https://doi.org/10.1155/2019/3075840

26 Nasiru M, Auta T, Bawa J Geohelminth contamination of fruits and vegetables cultivated on land irrigated with waste water in Gusau Local Government Area, Zamfara State, Nigeria. Zoologist. 2015;13:7-10.

27 Said D. Detection of parasites in commonly consumed raw vegetables. Alexandria J Med. 2012;48(4):345-352. doi:10.1016/j. ajme.2012.05.005

28 Duedu KO, Yarnie EA, Tetteh-Quarcoo PB, Attah SK, Donkor ES, Ayeh-Kumi PF. A comparative survey of the prevalence of human parasites found in fresh vegetables sold in supermarkets and open-aired markets in Accra, Ghana. BMC Res Notes. 2014;7(1). doi:10.1186/17560500- 7-836

29 Dada EO, Olusola-Makinde OO. Microbial and Parasitic Contamination on Vegetables Collected From Retailers in Main Market, Akure, Nigeria. Am J Microbiol Res. 2015;3(3):112-117. doi: 10.12691/ajmr-3-3-3.

30 Wharton, D. The production and functional morphology of helminth egg-shells. Parasitol. 1983;86(4):85- 97

31 Mogaji HO, Dedeke GA, Jaiyeola OA, Adeniran AA, Olabinke DO, Oluwole AS, Abe EM, Adeaga DO, Yusuff QA, Yusuff HÁ. A preliminary survey of School-based Water, Sanitation, Hygiene (WASH) Resources and soiltransmitted helminthiasis in eight public schools in Odeda LGA, Ogun State, Nigeria. Parasitology Open. 2017;3 (16), 1-10. https://doi.org/10.1017/pao.2017.18

32 Tefera T, Biruksew A, Mekonnen Z, Eshetu T. Parasitic contamination of fruits and vegetables collected from selected local markets of Jimma town, southwest Ethiopia. Int Sch Res Notices. 2014;1-7. doi:10.1155/2014/382715.

33 Dankwa K, Siaw D, Obboh E, Singh B, Nuvor S. Parasitic profile of fresh vegetables sold in selected markets of the Cape Coast Metropolis in Ghana. Annu Res Rev Biol. 2018;28(6):1-7. doi:10.9734/ARRB 